\title{
Isolation of Secondary Metabolites from Ipomea digitata L. Tuber Extracts and it's Effect on Cardiovascular Risk Parameters
}

\author{
GARIMA OJHA ${ }^{1,2 *}$, KAUSHAL NATH MISHRA ${ }^{2}$, HARPREET SINGH ${ }^{1}$, \\ and ARUN KUMAR MISHRA ${ }^{1}$
}

${ }^{1}$ Phytochemistry Research Laboratory, Faculty of Pharmacy, IFTM University, Moradabad, 244001, India. Institute of Technology and Management, GIDA, Gorakhpur-273001, India.

*Corresponding author E-mail: garimaojha24ddcip@gmail.com

http://dx.doi.org/10.13005/ojc/360110

(Received: December 01, 2019; Accepted: January 02, 2020)

\begin{abstract}
The objective of present investigation was to test the presence of various phytochemicals present in the ethanol extract (EE) of Ipomea digitata L. tuber and to isolate the active constituents present in the EE. Further it was aimed to evaluate the antioxidant activity using in vitro model and to assess the effects of extracts of Ipomea digitata L. on risk factors associated with cardiovascular disorders. Phytochemical tests were performed. After performing column chromatography, the isolated compounds were characterized by IR, ${ }^{1} \mathrm{H} N \mathrm{NM},{ }^{13} \mathrm{C}$ NMR and MS techniques. For antioxidant activity, 1,1-diphenyl-2-picrylhydrazyl (DPPH) method, Nitric oxide (NO) method and hydrogen peroxide $\left(\mathrm{H}_{2} \mathrm{O}_{2}\right)$ methods were used. The extraction yield for EE was found to be $6.66 \%$ and the extract was light brown in appearance with semisolid consistency. Two phytoconstituents of category viz. phytosterol ( $\beta$-sitosterol) and a coumarin (7-Hydroxy-4-methylcoumarin) were isolated and characterized. The findings suggested that the antioxidant activity of $E E$ is in dose dependent manner. Cholesterol rich diet fed to animals caused increased Albumin, Cholesterol and LDL-Cholesterol. Cholesterol rich diet also reduced the concentration of Serum Globulin, HDL-Cholesterol and Triglycerides (TG) when comparison was made with control group. Dosing of EE $(200 \mathrm{mg} / \mathrm{kg} \mathrm{b.w}$.) caused increased level of serum TG, HDL-Cholesterol and reduced level of LDL-Cholesterol when comparison was made with control, in the cholesterol rich diet offered rats. The result concluded the presence of number of secondary metabolites in EE of Ipomea digitata L. Moreover, the present paper reports the presence of $\beta$-sitosterol and 7-Hydroxy-4-methylcoumarin in the EE of Ipomea digitata L. very first time. Finding also suggests that EE may be explored as functional food in near future.
\end{abstract}

Keywords: Ipomea digitata L, Phytosterol, $\beta$-sitosterol, 7-Hydroxy-4-methylcoumarin, Antioxidant activity.

\section{INTRODUCTION}

It is very common fact that in contemporary time, people are moving towards herbalism. As we know, drugs which are of synthetic origin, shows some adverse effect on our body. In order to overcome this, the public at large is diverted towards green medicines, as they are effective as well as

This is an Open Access article licensed under a Creative Commons license: Attribution 4.0 International (CC- BY). Published by Oriental Scientific Publishing Company @ 2018

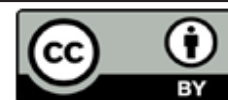


having least side effect on the physiological system. Since very ancient time, herbs are very rich source of effective medicaments; therefore these are beneficial to treat various ailments. In the contemporary times, public at large is taking interest about significance of medicinal plants. Plant based medicines are easily available, less expensive, safe, efficient and are economical also. Specific physiological actions on the human body are exerted by some organic compounds, which are present in medicinal plants and these compounds qare under category of alkaloids, glycosides, terpenes, carbohydrates and flavonoids ${ }^{1,2}$.

When discussing about cardiovascular risk parameters associated with obesity, this is defined as an excessive fat accumulation of adipose tissue which culminates into as cardiovascular diseases. The mechanism related with obesity associated with cardiovascular disease is high blood pressure which causes damage to the heart etc. Major risk factor includes enhanced level of LDL, reduced level of HDL etc. Blood profile analysis may be considered as marker for altered blood glucose, total cholesterol and HDL etc. In current years, natural products are considered as best alternatives for the treatment of obesity related complications. In contemporary times, there is need to search plants which can be beneficial to eradicate risk associated with the cardiovascular problems.

Ipomoea digitata $\mathrm{L}$. is one of the important plants, having reported good hypoglycemic, anti-inflammatory, anticonvulsant and aphrodisiac activity. The tribals are using still the paste of the powder of Ipomoea digitata L. to eliminate common cold and some cardiovascular problems. The traditional books claim their use as health supplement to rejuvenate physiological body system, antiobesity agent and also to remove the helminthes. Several tribes in India use Ipomoea digitata L. tuber material suspended in coconut oil or sesame oil for treatment of wounds ${ }^{3}$.

Ipomoea digitata L. is large sized, perennial climber with fleshy roots. Leaves of Ipomoea digitata L. possess long petioles with rounded outline at the base. The number of lobes is generally 5 to 7 on stalk of leaf. The shape of sepals is oval and length is $1 \mathrm{~cm}$ approximately. The capsules are ovoid and length is approximately $1 \mathrm{~cm}$ or less 4 . Botanical Classification of Ipomoea digitata L. is shown in Table 1 given below.

\begin{tabular}{cc}
$\begin{array}{c}\text { Table 1: Botanical Classification } \\
\text { Ipomoea digitata } L\end{array}$ \\
\hline Kingdom & Plantae \\
\hline Clade & Angiosperms \\
Clade & Eudicots \\
Clade & Asterids \\
Order & Solanales \\
Family & Convolvulaceae \\
Genus & Ipomoea \\
Species & Ipomoea digitata \\
\hline
\end{tabular}

Keeping in view the significant importance of this plant to treat various ailments, the present task was undertaken to test the presence of various phytochemicals using standard methods, to isolate and characterize bioactive compounds, to evaluate antioxidant potential using in vitro methods and to assess the various cardiovascular risk parameters. The key objective of present investigation was to scientifically prove the tuberous roots of Ipomoea digitata L. as antioxidant agent and to evaluate its effect on cardiovascular risk parameters. Ipomea digitata belongs to family Convolvulaceae. The tuberous roots are used as diuretic, anti-leprotic and antiemetic agent. Also it is used in the treatment of blood disease and helminthiasis 6 . Ipomea digitata L. is also employed as aphrodisiac and antimicrobial agent ${ }^{7}$. In one research conducted on isolation of active phytoconstituent, leaves and stems yielded resin glycosides upon column chromatography ${ }^{8}$. The tubers of this plant are generally used as a tonic, health supplement, galactogogue, demulcent, lactagogue, purgative, cholagogue. The plant is well reported for antioxidant and immunomodulatory activities $^{9,10,11,12}$.

\section{MATERIAL AND METHOD}

\section{Collection of Plant material and extraction}

Tuber of Ipomea digitata L. were collected from own farm house, Gorakhpur and authenticated from ABS BC Research and Training Centre, Salem, India. The tubers were shade-dried and coarsely powdered for further use.

The powdered crude tubers were subjected to Soxhlet extraction. About $2 \mathrm{~kg}$ of powdered tuber was uniformly packed into thimble and defatted 
using petroleum ether. The marc obtained was dried and further subjected to extraction using ethanol. The extraction was done for $72 \mathrm{~h}$, till the solvent in siphon tube become colorless. After that, ethanolic extract EE was taken in a flask and kept on rotary evaporator, till all the solvent got separated from EE. The dried EE was kept in a refrigerator at $4^{\circ} \mathrm{C}$ till its future use.

\section{Chemicals}

Silica Gel, DPPH, EDTA, Ascorbic acid and Perchloric acid were procured from Sigma-Aldrich, St. Louis, USA. All other chemicals and reagents as n-Hexane, Methanol, Petroleum ether, Ethanol, Naphthyethylene diamine dihydrochloride used were of analytical grade.

\section{Phytochemical Screening of Ipomea digitata L.} Preliminary phytochemical analysis of $E E$ of tuber of Ipomea digitata L. was performed by using standard protocols for the presence of saponins, coumarins, flavonoids, alkaloids, glycosides, proteins, carbohydrates, steroids and phytosterols etc. ${ }^{13}$

\section{Column Chromatography, Isolation and Spectroscopy based Characterization from EE}

The Column Chromatography was performed for EE $(2 \mathrm{~g})$ on silica gel packed column and for elution, n-Hexane: Methanol in different ratios were employed. The fractions from elute were collected and analyzed on TLC plate (Table 3). TLC based characterization revealed that in some cases, no spots were observed whereas, some showed prominent spots. The elute fractions with clear spots with same $R_{f}$ values were combined.

\section{Laboratory Test Animals}

In the present study, Male Wistar rats (220-250 g) were used. The rats $(n=6)$ were kept at temperature $\left(28 \pm 2^{\circ} \mathrm{C}\right)$ and $\mathrm{RH}(55-65 \%)$. A $12 \mathrm{~h}$ dark light cycle (12:12 h) was ensured during the experimentation. Animals were given free access to food and water. The protocols for experiments were approved (Ref. No.-2017/837ac/Ph.D./25) by the Institutional Animal Ethical Committee (IAEC) constituted under Committee for the Purpose of Control and Supervision of Experimental Animals (CPCSEA-837/ac/2004) guidelines.

\section{Experimental Design}

For experiments, animals were divided into five groups $n=6$ in each group.
Group 1 rats were given continuous 1\% high-cholesterol diet (HCD) along with Ad libitum.

In group 2 the rats were given HCD (84d), ethanolic extract $(100 \mathrm{mg} / \mathrm{kg})(7 \mathrm{~d})+$ Ad libitum.

Group 3 rats were given HCD (84d), with ethanolic extract $(200 \mathrm{mg} / \mathrm{kg})(7 \mathrm{~d})+$ Ad libitum.

Group 4 rats were given HCD with no extract.

Group 5 rats were neither given HCD food nor treated with EE (Control).

Groups 1, 2, 3 and 4 rats were fed with the cholesterol rich diet for eighty four (84) d. After the $84^{\text {th }} \mathrm{d}$, group 1 animals were provided the cholesterol rich diet till the $90^{\text {th }} \mathrm{d}$, whereas group 2 and group 3 animals were stopped on the cholesterol rich diet (after the $84^{\text {th }} \mathrm{d}$ ) and administered with EE of l. digitata tuber (100 mg/kg and $200 \mathrm{mg} / \mathrm{kg} \mathrm{b.w}$ ), till the $90^{\text {th }} \mathrm{d}$ (i.e. for a period of $7 \mathrm{~d}$ ). Also, after the $84^{\text {th }}$ $\mathrm{d}$, group 4 animals were stopped on the cholesterol rich diet and given normal diet till the $90^{\text {th }} \mathrm{d}$, while group 5 animals were neither provided cholesterol rich food nor they were treated with $\mathrm{EE}$, during experiments (control group).

\section{Incorporation of Extracts and Blood Withdrawal}

For the purpose of dosing, suspension was prepared using $2 \mathrm{~g}$ of extract. The suspension (extract) was given by oral route at a dose of 100 and $200 \mathrm{mg} / \mathrm{kg}$ b.w. for $6 \mathrm{~d}$.

After $84 \mathrm{~d}$ of cholesterol rich diet treatment and before start of treatment (i.e. Day 85) with the EE, blood was withdrawn. Also, on the $91^{\text {th }} \mathrm{d}$, upon treatment with the EE for 6 days, blood was withdrawn in similar way. The collected blood was stored at $25^{\circ} \mathrm{C}$ until analysis. The tubes of blood samples were subjected to centrifugation with speed $4000 \mathrm{rpm}$ for $15 \mathrm{~m}$ to get serum sample for further study.

\section{Evaluation of Biochemical Parameters}

Triacylglycerol (TG), Total Cholesterol $(\mathrm{CHL})$, and $\mathrm{HDL}-\mathrm{Cholesterol}(\mathrm{HDL})$ were quantified by the method as prescribed by standard methods. LDL-Cholesterol (LDL) was calculated by the formula as follows:

$(\mathrm{LDL}-$ Cholesterol $(\mathrm{mg} / \mathrm{dl})=$ Total Cholesterol -TG/5 - HDL Cholesterol)

In order to estimate the amount of glucose, total protein (Biuret method) and albumin, standard 
procedure as stated by previous researchers were followed. The difference between total serum protein and albumin was counted as amount of globin present in sample. All reagents were purchased from Diachi Chemical Co. Tokyo, Japan.

\section{Antioxidant Potential Evaluation (In vitro) DPPH Method}

The samples of EE of plant were prepared by dissolving it into DMSO and finally samples of 20 , 40, 60, 80, $100(\mu \mathrm{g} / \mathrm{ml})$ concentrations were prepared. For comparison, Ascorbic acid $(100 \mu \mathrm{g} / \mathrm{mL})$ was used. DPPH $(100 \mu \mathrm{g} / \mathrm{mL})$ in ethanol $(2 \mathrm{~mL})$ was mixed with equal volume of the diluted EE of Ipomea digitata in phosphate buffer $(\mathrm{pH}$ 7.3). The reaction mixture in properly wrapped test tube by aluminum foils were set aside for $20 \mathrm{~m}$ and kept away from light. The absorbance at $517 \mathrm{~nm}$ of DPPH was monitored in presence of different concentration of ethanol extract.

Measurement of absorbance of blank solution was performed with an aim to determine the absorbance of DPPH before the start of reaction with the EE. Inhibition (\%) of the radicals was calculated according to formula as follows.

$\%$ Inhibition $=\frac{\text { Acontral }- \text { Atest }}{\text { Acontroal }} \times 100$

\section{Nitric oxide radical scavenging activity ${ }^{15}$}

Sodium nitroprusside (SNP) is counted as source of Nitric oxide (NO) and it was measured using Griess reagent. SNP when reacted with saline phosphate buffer, upon reaction, it produces $\mathrm{NO}$ and this produced NO is measured by Griess reagent. SNP $(10 \mathrm{mM})$ in phosphate buffer saline was mixed with all prepared dilutions of EE $(20,40,60,80$, $100 \mu \mathrm{g} / \mathrm{mL}$ ) and resulting mixture were subjected to incubation at $25^{\circ} \mathrm{C}$ for $180 \mathrm{~m}$. The samples of above mixture were reacted with Griess reagent ( $1 \%$ sulphanilamide, $0.1 \%$ naphthyethylene diamine dihydrochloride and $3 \%$ phosphoric acid).

The measurement of absorbance of colored component, after the diazotization reaction of nitrite ion with sulphanilamide and then coupling reaction with naphthyethylene diamine dihydrochloride were measured using digital colorimeter at 546 $\mathrm{nm}$ wavelength. The absorbance of ascorbic acid was measured in similar process after reacting with Griess reagent was measured. In NO radical scavenging activity, again ascorbic acid was employed as sample for positive control.

No scavenged $(\%)=\frac{\text { Acontral }- \text { Atest }}{\text { Acontroal }} \times 100$

Where, $A_{\text {control }}=$ Absorbance of control reaction and $A_{\text {test }}=$ Absorbance in the presence of the samples of ethanolic extract. Each experiment was performed in triplicate and findings are presented as mean (\% scavenged activity) \pm SEM.

\section{$\mathrm{H}_{2} \mathrm{O}_{2}$ method for Free Radical Scavenging Activity. ${ }^{16}$}

The free radical (peroxide) scavenging capacity of EE of Ipomea digitata L. was evaluated using standard method. The reaction process involves the formation of hydroxyl radical using $\mathrm{Fe}^{+3}$ /ascorbate/ EDTA $/ \mathrm{H}_{2} \mathrm{O}$ with concept of Fenton reaction. This is one of the method in which hydroxyl radical produced is reacted with DMSO to produce formaldehyde. The reaction process resulted in formation of yellow colored product, which was subjected to measurement of absorbance at $412 \mathrm{~nm}$ using spectroscope, against blank solution. The hydroxyl radical scavenging potential is exhibited as \%inhibition.

\section{Statistical analysis}

The statistical analysis was performed, employing unpaired t-test or One Way ANOVA followed by Dunnett's test or comparative study. The software InStat - Pro version 0.3 was used for the analysis.

\section{RESULTS AND DISCUSSION}

\section{Extraction Yield and Physical Characteristics of EE of Ipomea digitata L. tuber}

The extraction yield for EE was found to be $6.66 \%$ and the extract was light brown in appearance with semisolid consistency.

\section{Preliminary Phytochemical Test ${ }^{13}$}

The preliminary phytochemical test performed on EE revealed the presence of carbohydrate, coumarins, glycosides, protein, amino acid, phytosterols, flavonoids, gum and mucilage whereas alkaloids, tannins and terpenoids were absent. On performing the phytochemical test for EE of tuber of Ipomea digitata L., the presence of undermentioned phytoconstituents were confirmed Table 2. 
Table 2: Phytochemical screening of tuber of Ipomea digitata L.

\begin{tabular}{cc}
\hline Phytochemical Test & Findings \\
\hline Alkaloids & - \\
Saponin & + \\
Steroids & + \\
Glycosides & + \\
Tannins & - \\
Flavonoids & + \\
Terpenoids & - \\
Amino acid & + \\
Carbohydrate & + \\
Phytosterols & + \\
Coumarins & + \\
\hline$+=$ Present; -=Absent &
\end{tabular}

The standard methods of phytochemical tests were used. As per study conducted by previous researcher, it was elucidated that the presence of coumarins and phytosterols are generally accountable for antioxidant activity ${ }^{17,18}$ and cardioprotective activity ${ }^{19,20}$.

\section{Isolation of Compounds}

\section{Isolation of Compound $\mathbf{1}$ and Compound $\mathbf{2}$}

Five eluted fractions (11-15) using solvent system n-hexane: methanol (1.6: 0.4) in column chromatographic study was collected. The values of $\mathrm{R}_{f}(0.51)$ of all these collected fractions were found same in mobile phase $n$-hexane: methanol (1.6:0.4) in TLC. Due to similar $R_{f}$ of all these fraction, the fractions were combined (Fraction Code F-3). Afterwards, F-3 was concentrated and resulted into a single clear spot over TLC plate. The yield was $20 \mathrm{mg}$. Visualization of spot was done in UV light at $366 \mathrm{~nm}$. Further the Compound 1 was subjected to recrystallization from ethanol and finally white shinning crystals were obtained; melting point range $\left(134-136^{\circ} \mathrm{C}\right)$.

In addition to this, five eluted fractions (26-30) using solvent system [n-hexane: methanol (1.0:1.0)] by Column chromatography were collected. $R_{f}$ value of all these fractions were same using mobile phase [n-hexane: methanol (1.0:1.0) in TLC. This was the reason behind combining all of these fractions (Fraction code: F-6). F-6 showed similar $R_{f}$ value $(0.41)$ in the mobile phase; [n-hexane: methanol (1.0:1.0). F-6 was concentrated and gave a single spot over TLC to yield $13 \mathrm{mg}$. A spot was visualized using UV light at $366 \mathrm{~nm}$. Compound 2 was recrystallized from ethanol as white shinning crystals; melting point range $\left(188-190^{\circ} \mathrm{C}\right)$.

Table 3: Fractions collected by Column Chromatography of EE of Ipomea digitata L. tuber

\begin{tabular}{|c|c|c|c|c|c|}
\hline S.No & Solvent for Elution & Ratio & $\begin{array}{l}\text { Eluted Fractions, Collected } \\
\text { after Column Chromatography }\end{array}$ & $\begin{array}{l}\text { Visualization } \\
\text { after TLC }\end{array}$ & $\begin{array}{l}\text { Code assigned } \\
\text { for Fractions }\end{array}$ \\
\hline 1 & n-Hexane : Methanol & $2.0: 0.0$ & $1-5$ & No spot & $\mathrm{F}-1$ \\
\hline 2 & n-Hexane : Methanol & $1.8: 0.2$ & $5-10$ & No spot & $\mathrm{F}-2$ \\
\hline 3 & n-Hexane : Methanol & $1.6: 0.4$ & $11-15$ & Clear & $\mathrm{F}-3$ \\
\hline 4 & n-Hexane : Methanol & $1.4: 0.6$ & $16-20$ & Tail & $\mathrm{F}-4$ \\
\hline 5 & n-Hexane : Methanol & $1.2: 0.8$ & $21-25$ & Not clear & $\mathrm{F}-5$ \\
\hline 6 & n-Hexane : Methanol & 1.0:1.0 & $26-30$ & Clear & $\mathrm{F}-6$ \\
\hline 7 & n-Hexane : Methanol & $0.8: 1.2$ & $31-35$ & Not clear & $\mathrm{F}-7$ \\
\hline 8 & n-Hexane : Methanol & $0.6: 1.4$ & $36-40$ & Not clear & $\mathrm{F}-8$ \\
\hline 9 & n-Hexane : Methanol & $0.4: 1.6$ & $41-45$ & No spot & $\mathrm{F}-9$ \\
\hline 10 & n-Hexane : Methanol & $0.2: 1.8$ & $46-50$ & No spot & $\mathrm{F}-10$ \\
\hline 11 & n-Hexane : Methanol & $0.0: 0.2$ & $51-55$ & Tail & $\mathrm{F}-11$ \\
\hline
\end{tabular}

The recrystallized isolates were characterized using sophisticated analytical spectroscopic techniques (IR, proton NMR, $\mathrm{C}^{13} \mathrm{NMR}$ and mass spectroscopy).

\section{Characterizations of Compounds}

Compound 1 was a white in color, obtained from fraction $3(F-3)$ of EE. Melting point was measured to be $134-137^{\circ} \mathrm{C}$. The UV spectrum of compound 1 showed absorbance peak at $\lambda_{\text {max }}: 254$ $\mathrm{nm}$ in ethanol. IR: $(\mathrm{KBr}) \mathrm{v}:\left[3334 \mathrm{~cm}^{-1}(\mathrm{OH}\right.$ stretching in associated state), $2958 \mathrm{~cm}^{-1}$ (Assymetric $\mathrm{CH}_{2}$ stretching) for cyclohexane, $1650 \mathrm{~cm}^{-1}(\mathrm{C}=\mathrm{C}$ stretching), $1450 \mathrm{~cm}^{-1}$ (C-H bending of cyclopentane), $1380 \mathrm{~cm}^{-1}, 1062 \mathrm{~cm}^{-1}$ (less characteristic), $881 \mathrm{~cm}^{-1}$ (=C-H bending). ${ }^{1} \mathrm{H}$ NMR: $\delta$ (ppm) 7.65 (s, O-H), 5.65 (m,1H, H-6), 3.51 (tdd, 1H, H-3), 1.25 (s, 3H, H-19), 1.16 (s, 3H, H-18), 1.02 (s, 3H, H-26), 1.01 (s,3H, $\mathrm{H}-27), 0.92$ (s,3H,H-21), 0.91 (s,3H,H-29). ${ }^{13} \mathrm{C}$ NMR:

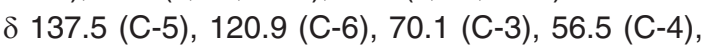
56.2 (C-17), 48.2 (C-14), 41.3 (C-13), 40.7 (C-10), 
34.6 (C-20), 31.9 (C-25, C-26), 29.1 (C-23), 26.2 (C-12), 20.2 (C-18, C-19), 19.3 (C-21), 16.5 (C-29), 12.8 (C-27).

\section{Mass spectroscopy}

Mass spectroscopy of isolated compound 1 showed that the molecular formula $\mathrm{C}_{29} \mathrm{H}_{50} \mathrm{O}$. Based on ES-MS data $\mathrm{m} / \mathrm{z}$ was 414.75 and calculated molecular weight was 414 . Compound 1 was identified as $\beta$-Sitosterol by comparison of physical parameters, IR, ${ }^{1} \mathrm{HNMR}$ spectra, ${ }^{13} \mathrm{C}$ NMR and mass spectra with reported data (Figure 1).

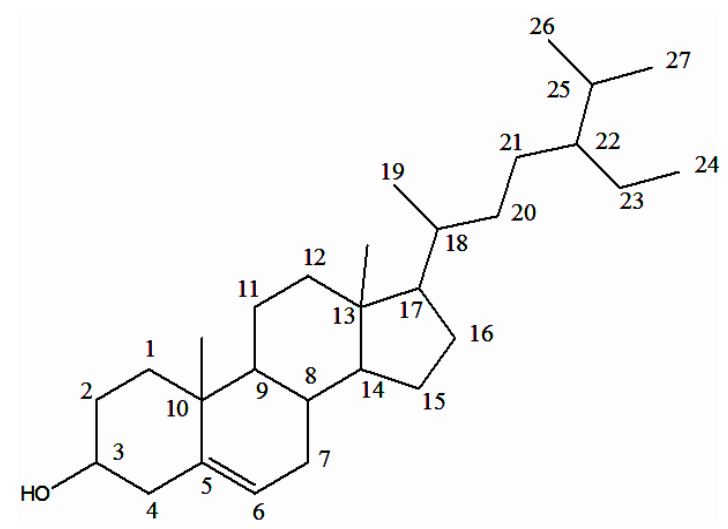

Fig. 1. $\beta$-Sitosterol

Compound 2 was a yellow solid, purified by crystallization using ethanol as solvent obtained from fraction $6(F-6)$ of EE. Melting point was measured and found to be $188-190^{\circ} \mathrm{C}$. The UV spectrum of compound 2 showed maximum absorbance at $\lambda_{\max }$ : $222 \mathrm{~nm}$ in ethanol. IR: $(\mathrm{KBr})$ v: $3421 \mathrm{~cm}^{-1}(\mathrm{OH})$, $2937.05 \mathrm{~cm}^{-1}$ (olefinic-CH stretching), 1700 and $1681 \mathrm{~cm}^{-1}$ (unsaturated lactone carbonyl), 1651.2 $\mathrm{cm}^{-1}$ (tri-substituted double bond), 1580.9, 1455.57 $\mathrm{cm}^{-1}$ (aromatic ring), 1369.4, 1214.1, 1159.1, 1088.8 $\mathrm{cm}^{-1}$ (C-O stretching). ${ }^{1} \mathrm{HNMR}$ : $\delta 2.52(\mathrm{~s}, 3 \mathrm{H}), 7.42$ $(\mathrm{m}, 1 \mathrm{H}), 6.84(\mathrm{~m}, 2 \mathrm{H}), 5.28(\mathrm{~s}, 1 \mathrm{H}), 2.62(\mathrm{~m}, 1 \mathrm{H})$. ${ }^{13} \mathrm{C}$ NMR: (125 MHz, DMSO-d, $\delta, \mathrm{ppm}$ ): 162.31 (lactone carbonyl), 160.55, 153.88, 153.15, 125.38, $113.15,111.05,109.88,104.25$ (aromatics and alkenes), $18.18\left(-\mathrm{CH}_{3}\right)$.

\section{Mass spectroscopy}

Mass spectroscopy of isolated compound 2 showed that the molecular formula of the compound was $\mathrm{C}_{10} \mathrm{H}_{8} \mathrm{O}_{3}$ and based upon ES-MS data, $\mathrm{m} / \mathrm{z}$ 176.13 and calculated molecular weight was 176.17 . Compound 2 was identified as 7 -hydroxy-4-methyl coumarin by comparison of physical parameters, IR,
${ }^{1} \mathrm{HNMR}$ spectra, ${ }^{13} \mathrm{C}$ NMR and mass spectra with reported data (Figure 2).<smiles>Cc1cc(=O)oc2cc(O)ccc12</smiles>

Fig. 2. 7-hydroxy-4-methyl coumarin

\section{Cardiovascular risk parameters}

The effect of administration of EE (100 $\mathrm{mg} / \mathrm{kg} \mathrm{bw}$ ) of Ipomea digitata tuber on blood serum parameters in rat, treated with cholesterol rich diet are presented in Table 4. The effect of cholesterol rich diet for $84 \mathrm{~d}$ on cholesterol level on the mean serum cholesterol $(\mathrm{CHL})$, triglycerides (TG), HDL cholesterol (HDL-CH) and LDL-cholesterol (LDL-CH) levels $(\mathrm{mg} / \mathrm{dl})$ of animals are presented. All the rats were fed with cholesterol rich diet (groups 1, 2, 3 and 4) exhibited significantly $(P<0.05)$ increased amount of $\mathrm{CHL}$, LDL-CH and reduced levels of TG, HDL$\mathrm{CH}$ when comparison was made with the control (group 5), after $84 \mathrm{~d}$ of HCD intake. Administration of the two doses of extracts $(100 \mathrm{mg} / \mathrm{kg}$ and 200 $\mathrm{mg} / \mathrm{kg}$ ) of I. digitata tuber, for a period of 6 days, resulted in significantly $(P>0.05)$ reduced levels of $\mathrm{CHL}$, LDL-CH and higher TG, HDL-CHL levels. The effect of HCD for 84 days on the mean plasma glucose, serum albumin, globulin and total protein levels $(\mathrm{mg} / \mathrm{dl})$ in normal rat are presented in Table 5. The animal treated with HCD exhibited significantly $(P<0.05)$ increased the concentration of albumin and reduced levels of globulin, in comparison to control (group 5), after $84 \mathrm{~d}$ of HCD diet. Administration of the extracts (EE in $100 \mathrm{mg} / \mathrm{kg}$ and $200 \mathrm{mg} / \mathrm{kg}$ ) of Ipomea digitata tuber for $6 \mathrm{~d}$ resulted in significantly $(P>0.05)$ lower amount albumin, total protein and significantly increased levels of globulin.

Increased risk of cardiovascular system is related with a reduction in $\mathrm{HDL} \mathrm{CHL}{ }^{21}$. Apart from this, change in TG also accounts for altered parameters. In general, it is said that level of serum TG reduces due to high fatty diet in animals. The present study defines that $E E(200 \mathrm{mg} / \mathrm{kg})$ is enough potent to reduce the glucose level and higher serum TG level in comparison to untreated group. The increased $\mathrm{CHL}$ may be due to hepatic cirrhosis. The reduced $\mathrm{CHL}$ levels after EE treatment may be 
due to the phytosterols especially $\beta$-Sitosterol and Coumarins as reported by previous researchers. The plasma cholesterol-lowering properties ${ }^{10}$ of plant sterols have been known since the 1950s.

The phytosterol lowers serum $\mathrm{CHL}$ by preventing the absolute absorption of dietary and endogenously derived phytosterols.

$\mathrm{CHL}$ present in HDL is generally counted as beneficial for good cardiovascular health, but in opposite to this, LDL- cholesterol is counted as harmful for the same. HDL works in a way to remove the $\mathrm{CHL}$ from hepatic peripheral cells. At this point, $\mathrm{CHL}$ gets changed into bile acid which further gets excreted through intestine ${ }^{21}$. This action is affected by $\mathrm{CHL}$ rich diet because it causes reduction in HDL-CHL level in laboratory animals. After 1 week of treatment with the EE of Ipomea digitata L. tuber, the HDL- cholesterol levels were seen to be significantly higher in the treated groups, when compared with the untreated group. This indicates the beneficial effect of the plant with respect to cardiovascular risks.
There is a strong link among cholesterol rich diet, serum cholesterol concentration and the occurrence of coronary heart disease.

As this plant is enough potent to reduce the total plasma level, this may be potent hypoglycemic agent also. Total protein (TP), tells about the functional status of the hepatic cells ${ }^{22}$. EE caused reduction in TP. Reduced TP may be connected with liver protein content, which is lower in EE $(100 \mathrm{mg} / \mathrm{kg})$ and higher in the EE $(200 \mathrm{mg} / \mathrm{kg})$. Cholesterol rich diet resulted in significantly higher serum albumin $(\mathrm{g} / \mathrm{dl})$ in all the groups. Albumin helps in transporting small molecules through the blood, including bilirubin, calcium, progesterone and medications ${ }^{23}$. The administration of the EE resulted in no change in the serum albumin levels of the treated groups. The globulins are accountable for immunity against microorganisms. EE resulted in an increase in the globulin content. This may be associated with the phytochemical constituents including phytosterols and saponins which are associated with immunological response.

Table 4: Serum CH, TG, HDL-CHL, LDL-CHL(mg/dl) of HCD diet rats treated with EE of Ipomea digitata tuber, continuous HCD, HCD+non-treated, no HCD and no treatment

\begin{tabular}{lcccccc}
\hline Blood Serum & & \multicolumn{5}{c}{ Groups } \\
& Days & I & II & III & IV & V \\
\hline CHL(mg/dl) & 84 & $92.61 \pm 6.08$ & $93.14 \pm 6.10$ & $95.81 \pm 8.57$ & $90.50 \pm 3.16$ & $59.44 \pm 6.12$ \\
& 90 & $98.96 \pm 6.16$ & $70.48 \pm 3.22$ & $62.32 \pm 6.54$ & $85.91 \pm 2.12$ & $62.25 \pm 5.62$ \\
TG(mg/dl) & 84 & $75.48 \pm 8.16$ & $75.18 \pm 7.84$ & $71.09 \pm 8.40$ & $74.75 \pm 2.34$ & $119.22 \pm 9.34$ \\
& 90 & $70.23 \pm 4.43$ & $84.14 \pm 4.15$ & $89.22 \pm 5.18$ & $77.44 \pm 4.81$ & $119.40 \pm 8.98$ \\
HDL(mg/dl) & 83 & $48.31 \pm 1.33$ & $45.81 \pm 4.53$ & $45.28 \pm 5.56$ & $44.91 \pm 5.91$ & $87.12 \pm 1.14$ \\
& 90 & $42.24 \pm 3.13$ & $66.77 \pm 6.81$ & $64.54 \pm 2.61$ & $48.66 \pm 2.80$ & $85.47 \pm 6.84$ \\
LDL(mg/dl) & 84 & $14.81 \pm 5.28$ & $13.40 \pm 4.20$ & $12.96 \pm 5.82$ & $15.12 \pm 1.80$ & $-12.02 \pm 4.40$ \\
& 90 & $17.14 \pm 6.17$ & $6.09 \pm 5.34$ & $4.18 \pm 5.04$ & $11.04 \pm 4.12$ & $-11.81 \pm 3.18$ \\
\hline
\end{tabular}

Table 5: Effect of EE treatment on Blood Plasma Glucose ( $\mathrm{mg} / \mathrm{dl})$ and Serum Albumin, Globulin, Total Protein (g/dl) level

\begin{tabular}{lcccccc}
\hline Blood Plasma & & \multicolumn{5}{c}{ Groups } \\
& Days & I & III & IV & V \\
\hline \multirow{2}{*}{ Glucose (mg/dl) } & 84 & $75.13 \pm 8.82$ & $74.33 \pm 8.13$ & $76.48 \pm 5.85$ & $75.53 \pm 6.22$ & $94.88 \pm 5.05$ \\
& 90 & $73.75 \pm 2.76$ & $67.75 \pm 0.84$ & $66.28 \pm 0.88$ & $81.23 \pm 4.52$ & $95.38 \pm 4.54$ \\
Serum Albumin (g/dl) & 84 & $7.33 \pm 0.74$ & $7.15 \pm 1.06$ & $4.89 \pm 0.42$ & $6.40 \pm 0.55$ & $2.98 \pm 0.16$ \\
& 90 & $8.08 \pm 0.08$ & $4.58 \pm 0.48$ & $1.72 \pm 0.35$ & $5.47 \pm 0.34$ & $2.84 \pm 0.24$ \\
Serum Globulin (g/dl) & 83 & $2.16 \pm 0.83$ & $2.08 \pm 0.28$ & $0.87 \pm 1.02$ & $2.27 \pm 0.14$ & $3.62 \pm 1.28$ \\
& 90 & $2.02 \pm 0.32$ & $2.95 \pm 0.96$ & $1.05 \pm 0.26$ & $2.36 \pm 0.52$ & $3.72 \pm 0.68$ \\
Serum Total Protein $(\mathrm{g} / \mathrm{dl})$ & 84 & $7.48 \pm 0.16$ & $7.66 \pm 0.15$ & $5.11 \pm 1.58$ & $7.18 \pm 0.08$ & $7.38 \pm 1.04$ \\
& 90 & $7.11 \pm 0.24$ & $5.02 \pm 0.34$ & $3.80 \pm 0.19$ & $7.62 \pm 0.34$ & $7.55 \pm 0.85$ \\
\hline
\end{tabular}




\section{In vitro antioxidant activity}

The phytosterols and coumarins are generally counted as potent moiety to encounter the free radicals. The free radicals are quenched by herbal antioxidants. In the present work, DPPH, $\mathrm{NO}$ and $\mathrm{H}_{2} \mathrm{O}_{2}$ methods were used to evaluate the antioxidant potential of EE. Plant based antioxidants have radical scavenging capacity and these are assumed to exert the protective consequence in contrast to free radical damage. These biomolecules may account to the inhibition of various ailments including cancer and cardiovascular disease including atherosclerosis, diabetes, asthma, hepatitis and arthritis ${ }^{24,25}$. The ingestion of natural diet, prepared with spices, medicinal and aromatic herbs has increased the interest among users and scientists because these spices and herbs exhibit antioxidant properties associated with a range of bioactive phytochemicals ${ }^{26,27}$. Due to enhanced interest in antioxidants, with an aim to avoid the supposed toxic effects of free radicals in the human body and to preclude degradation of fat content, phytochemicals as antioxidant, health supplement and as a rejuvenators are more preferred ${ }^{28}$.

For in vitro antioxidant activity evaluation, DPPH method is most common. Secondary metabolites in plants are found in abundance. It has been proved that the free radical scavenging potential of phenol is mainly due to their redox potentials, hydrogen donors and singlet oxygen quenchers ${ }^{29}$.

The antioxidant activity was evaluated using three different in vitro models viz. DPPH method, $\mathrm{NO}$ method and $\mathrm{H}_{2} \mathrm{O}_{2}$ method. Finding are present in Table 6. The change in color of DPPH is directly proportional to the amount of antioxidant present in the EE of Ipomea digitata L. The $100 \mu \mathrm{g} /$ $\mathrm{mL}$ concentration of EE of Ipomea digitata L. was found to be most potent free radical scavenger with antioxidant activity.

Table 6: \% Inhibition of free radicals by different concentration of EE of tuber of Ipomea digitata L.

\begin{tabular}{|c|c|c|c|c|c|c|c|c|}
\hline \multirow[t]{2}{*}{ S. No. } & \multirow[t]{2}{*}{ Method } & \multicolumn{7}{|c|}{ Concentration and its Free Radical Inhibition (\%) } \\
\hline & & $20 \mu \mathrm{g} / \mathrm{ml}$ & $40 \mu \mathrm{g} / \mathrm{ml}$ & $60 \mu \mathrm{g} / \mathrm{ml}$ & $80 \mu \mathrm{g} / \mathrm{ml}$ & $100 \mu \mathrm{g} / \mathrm{ml}$ & $\begin{array}{l}\text { Standard(Ascorbic } \\
\text { Acid } 100 \mu \mathrm{g} / \mathrm{ml} \text { ) }\end{array}$ & $\mathrm{IC}_{50}$ \\
\hline 1 & DPPH method & $15.11 \pm 0.001$ & $26.13 \pm 0.002$ & $46.12 \pm 0.003$ & $62.22 \pm 0.005$ & $82.25 \pm 0.001$ & $94.62 \pm 0.002$ & 65.12 \\
\hline 2 & NO method & $11.52 \pm 0.001$ & $21.52 \pm 0.003$ & $32.12 \pm 0.003$ & $45.22 \pm 0.002$ & $58.15 \pm 0.006$ & $96.12 \pm 0.001$ & 86.09 \\
\hline 3 & Hydroxyl Radical method & $15.30 \pm 0.002$ & $32.11 \pm 0.001$ & $46.12 \pm 0.000$ & $61.12 \pm 0.003$ & $88.11 \pm 0.001$ & $92.19 \pm 0.002$ & 63.48 \\
\hline
\end{tabular}

Data is presented as mean \pm SEM (Triplicate)

Similarly when nitric oxide (NO) method was employed on EE of Ipomea digitata L., the concentration of EE evaluated from $20 \mu \mathrm{g} / \mathrm{mL}$ to $100 \mu \mathrm{g} / \mathrm{mL}$ resulted \%inhibition ranging from 11.52 to $58.15 \%$.

In the same way, upon hydrogen peroxide method application, EE of Ipomea digitata L. in above concentration range, exhibited free radical inhibition (\%) ranging 15.3-88.11\%. Highest \% inhibition was $88.11 \%$, which was due to maximum concentration of $E E$.

$\mathrm{IC}_{50}$ value for present study using DPPH, $\mathrm{NO}$ and hydroxyl radical methods was found to be $5.12 \mu \mathrm{g} / \mathrm{mL}, 3.89 \mu \mathrm{g} / \mathrm{mL}$ and $5.48 \mu \mathrm{g} / \mathrm{mL}$ simultaneously. The $\mathrm{IC}_{50}$ value was measured and presented in Table 6.
The outcome of study revealed the potent antioxidant action of EE of Ipomea digitata L. This also suggests that EE may also be used as wound healing agent and health tonic and health supplement because of its potent free radical quenching effect. Highest antioxidant potential was observed for ascorbic acid (Standard). Keeping in view the presence of $\beta$-Sitosterol and 7-hydroxy4-methylcoumarin in EE, these two secondary metabolites may be considered as accountable for wound healing and antioxidant activity. The findings further suggest that the EE of Ipomea digitata L. may be used to formulate semisolid preparation which may be used to heal the wound and powder extract may be as antioxidant source.

\section{CONCLUSION}

The literature data suggest that phytosterols 
and coumarins are such secondary metabolites which can quench the free radicals and also minimize the risk associated with cardiovascular diseases. The improvement in cardiovascular problems is also observed as inter-linked with antioxidant potential. The study revealed the presence of $\beta$-sitosterol and 7-Hydroxy-4-methylcoumarin in EE. The possible reason for improvement in cardiovascular parameters and antioxidant activity may be associated with presence of two secondary metabolites. The phytosterols and coumarins, due to the presence of their phenolic hydroxyl groups are highly capable of scavenging free radicals and are known to be potent natural antioxidants ${ }^{29}$.

The finding of phytochemical analysis, revealed the presence of phytosterols and coumarins, and as because of presence of these two phytoconstituents, the EE may be potent enough to quench the free radicals generated by DPPH, NO and $\mathrm{H}_{2} \mathrm{O}_{2}$.

The result concluded the presence of carbohydrate, phytosterols, coumarins, glycoside, protein, amino acid, flavonoids, gum and mucilage in EE of Ipomea digitata L. Two compounds, a phytosterol ( $\beta$-sitosterol) and a coumarin (7-Hydroxy4-methylcoumarin) were isolated from EE of Ipomea digitata L. tuber which may be accountable for improvement in cardiovascular parameters and antioxidant activity of EE. It was observed that EE of tuber of Ipomea digitata L. exhibited antioxidant activity, highest at $100 \mu \mathrm{g} / \mathrm{mL}$.

High cholesterol diet caused increase in LDL-CHL, TCH, albumin and reduction in TG, HDL$\mathrm{CHL}$ and globulin level as these are considered as cardiovascular risk parameters. The finding suggested that treatment with I. digitata tuber EE reduces serum LDL-CHL, TCHL, albumin, protein (Total). In parallel, this also causes increase amount of HDL-CHL, globulin which are beneficial to eradicate cardiovascular problems. Therefore, Ipomoea digitata may be employed in the treatment of cardiovascular disorders.

\section{ACKNOWLEDGMENT}

Authors are grateful to the Faculty of Pharmacy, I.T.M, GIDA, Gorakhpur and DDCIP, Kanpur for continuous encouragement and providing necessary chemicals and facility in order to complete this research work. The present work is part of Ph. D. degree, from IFTM University, Moradabad, 244001, India.

\section{Conflict of Interests}

None declared.

\section{REFERENCES}

1. Edoga HO:, Okwu DE:, Mbaebie BO. Phytochemicals constituents of some Nigerian medicinal plants. Afr. J. Biotech., 2006, 4(7), 685-688.

2. Mann J. Secondary Metabolism. Oxford University Press., 1978, 154.

3. Sharma P.DravyaGuna-Vigyan (AubhidAusadhDravya), Chaukhambha Bhartiya Academy. Varanasi, India., 2001, 131-132.

4. Dasaroju S:, Gottumukkala KM. Current Trends in the Research of Emblica officinalis: A Pharmacological Perspective. Int. J. Pharm. Sci. Rev. Res., 2014, 24(2), 150-159.

5. Bendre AM:, Kumar A. A Text Book of Practical Botany. Rastogi Publiications, $7^{\text {th }}$ edition, Meerut, India., 2016, 76.

6. Chandira M:, Jayakar B. Formulation and evaluation of herbal tablets containing Ipomea digitata Linn extract. Inter. J. Pharm. Sci. Rev. Res., 2010, 3(1), 101-110.
7. Locher CP:, Burch MT:, Mower HF:, Beretecky J:, Davis H:, Vanpoel B:, Lasure A:, Vanden Berghe DA:, Vlietinck AJ. Antimicrobial activity and anti-complement activity of extracts obtained from selected Hawaiian medicinal plants. J. Ethnopharm., 1995, 49(1), 23-32.

8. Ono M:, Fukuda H:, Muraya H:, Miyahara K. Resin glycosides from the leaves and stems of Ipomoea digitata. Nat. Med., 2009, 63(2), 176-180.

9. Chopra RN:, Nayar SL:, Chopra IC. Glossary of Indian Medicinal Plants. C.S.I.R. Publishers., New Delhi., 1956, 142.

10. Kirtikar KR:, Basu BD. Indian Medicinal Plants., 1918, 877.

11. Nadkarni KM:, Nadkarni AK. Indian Materia Medica., 1954, 3, 686.

12. Upadhyay SN:, Immunodulation. Narosa Publishing House. India., 1997, 120-126. 
13. Khandelwal KR:, Practical Pharmacognosy, Nirali Prakshan., 2008, 16, 149-156.

14. Blois MS:, Antioxidant determination by the use of a stable free radical. Nat. Int. J. Sci., 1958, 181, 1199-1200.

15. Babu BH:, Shylesh BS:, Padikkala J. The Antioxidant and hepatoprotective effect of Alanthus icicifocus. Fitoter., 2001, 72, 272-277.

16. Vasagam AG:, Muthu, KA:, Manavalan RA. An In vitro Free Radical Scavenging Activity of Methanolic Extracts of Whole Plant of Teramnus labialis (Linn.). Int. J. Pharm. Chem. Sci., 2012, 1(3), 575-580.

17. Kadhum AAH:, Al-Amiery AA:, Musa AY:, Mohamad AB. The Antioxidant Activity of New Coumarin Derivatives. Int. J. Mol. Sci., 2011, 12(9), 5747-5761.

18. Shah SMA:, Akram M:, Riaz M:, Munir N:, Rasool G. Cardioprotective Potential of PlantDerived Molecules: A Scientific and Medicinal Approach. Dos. Res., 2019, 17(2), 1-14.

19. Cabral CE:, Klein MRST. Phytosterols in the Treatment of Hypercholesterolemia and Prevention of Cardiovascular Diseases. Arg. Bras. Cardiol., 2017, 109(5), 475-482.

20. Hsu CC:, Kuo HC:, Huang KE. The Effects of Phytosterols Extracted from Diascorea alata on the Antioxidant Activity, Plasma Lipids, and Hematological Profiles in Taiwanese Menopausal Women. Nut., 2017, 9(12), 1-14.

21. Mahdy AK:, Wonnerth A:, Huber K:, Wojta J. Cardiovascular disease risk reduction by raising HDL cholesterol-current therapies and future opportunities. Br. J. Pharm., 2012, 167(6), 1177-1194.
22. Pandey AK:, Gupta PP:, Lal VK. Preclinical evaluation of hypoglycemic activity of Ipomoea digitata tuber in streptozotocin-induced diabetic rats. J. Bas. Clin. Physiol. Pharmacol., 2013, 24(1), 35-39.

23. Omega K:, Azeke MA:, Omage SO. Evaluation of the efficacy of Acalypha wilkesiana leaves in managing cardiovascular disease risk factors in rabbits exposed to salt-loaded diets. Clin. Phytosci., 2018, 4(1), 1-7.

24. Lindley MG. The impact of food processing on antioxidants in vegetable oils, fruits and vegetables. Trend. Food. Sci. Tech., 1998, 8(9), 336-340.

25. Middleton E:, Kandaswamy C:, Theoharides TC. The effects of plant flavonoids on mammalian cells: Implications for inflammation, heart disease, and cancer. Pharm. Rev., 2000, 52, 673-751.

26. Salah N:, Miller NJ:, Pagang G:, Tijburg L:, Rice-Evans C. Polyphenolic flavonols as scavengers of aqueous phase radicals and as chain-breaking antioxidants. Arch. Biochem. Biophys., 1995, 322(2), 339-346.

27. Whitehead TP:, Robinson D:, Allaway S. Effect of red wine ingestion on the antioxidant capacity of serum. Clin. Chem., 1995, 41, 32-35.

28. Abdalla AE:, Roozen, JP. Effect of plant extracts on the oxidative stability of sunflower oil and emulsion. Food. Chem., 1999, 64, 323-329.

29. Habila JD:, Bello IA:, Dzikwi AA:, Musa H:, Abubakar N. Total phenolics and antioxidant activity of Tridax procumbens L. Afr. J. Pharm. Pharm., 2010, 4, 123-126. 